\title{
Proposed Methodology for a Tour-Based Freight Model
}

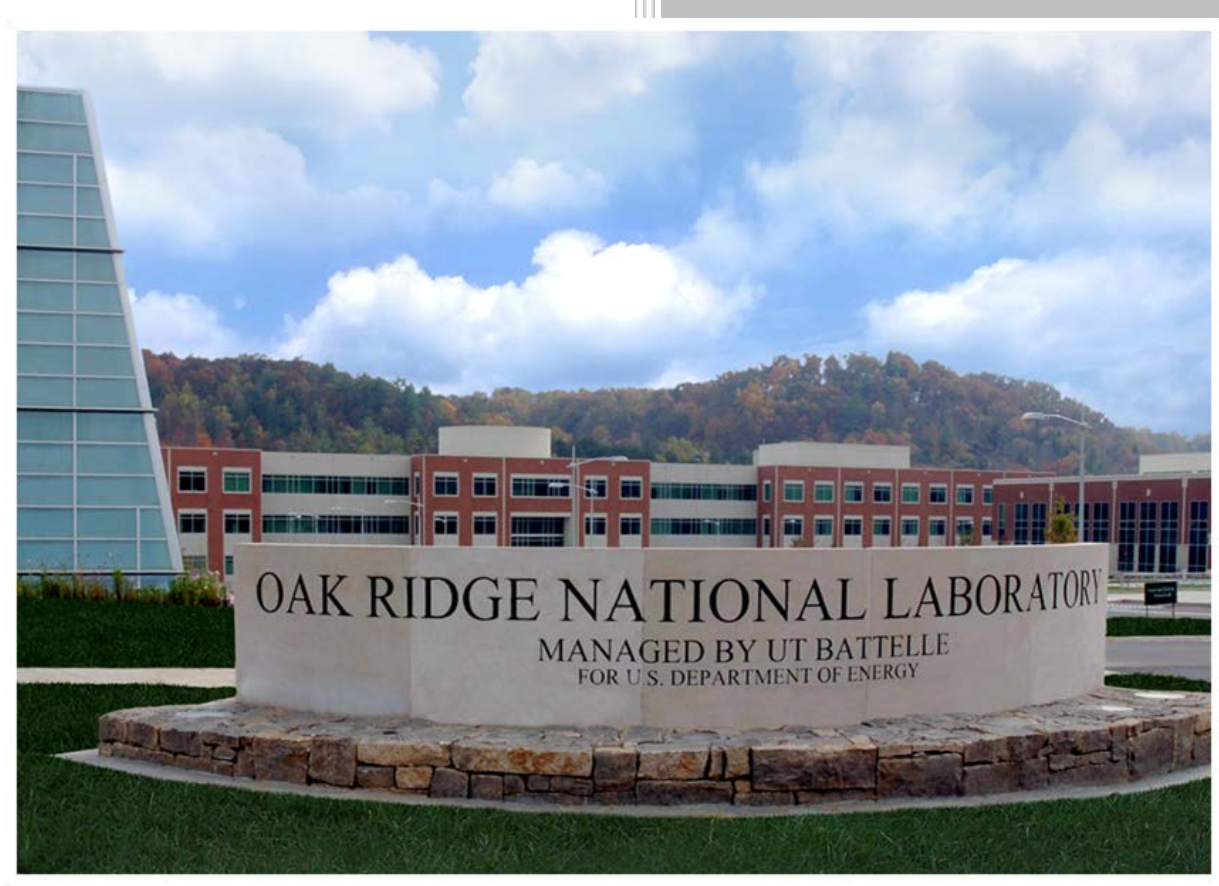

Approved for public release. Distribution is unlimited.
Amy M. Moore, Ph.D.

September 2017 


\title{
DOCUMENT AVAILABILITY
}

Reports produced after January 1, 1996, are generally available free via US Department of Energy (DOE) SciTech Connect.

Website http://www.osti.gov/scitech/

Reports produced before January 1, 1996, may be purchased by members of the public from the following source:

\author{
National Technical Information Service \\ 5285 Port Royal Road \\ Springfield, VA 22161 \\ Telephone 703-605-6000 (1-800-553-6847) \\ TDD 703-487-4639 \\ Fax 703-605-6900 \\ E-mail info@ntis.gov \\ Website http://classic.ntis.gov/
}

Reports are available to DOE employees, DOE contractors, Energy Technology Data Exchange representatives, and International Nuclear Information System representatives from the following source:

Office of Scientific and Technical Information

PO Box 62

Oak Ridge, TN 37831

Telephone 865-576-8401

Fax 865-576-5728

E-mail reports@osti.gov

Website http://www.osti.gov/contact.html

This report was prepared as an account of work sponsored by an agency of the United States Government. Neither the United States Government nor any agency thereof, nor any of their employees, makes any warranty, express or implied, or assumes any legal liability or responsibility for the accuracy, completeness, or usefulness of any information, apparatus, product, or process disclosed, or represents that its use would not infringe privately owned rights. Reference herein to any specific commercial product, process, or service by trade name, trademark, manufacturer, or otherwise, does not necessarily constitute or imply its endorsement, recommendation, or favoring by the United States Government or any agency thereof. The views and opinions of authors expressed herein do not necessarily state or reflect those of the United States Government or any agency thereof. 
Energy and Environmental Science Division

\title{
PROPOSED METHODOLOGY FOR A TOUR-BASED FREIGHT MODEL
}

Amy M. Moore, Ph.D.

Date Published: September 2017

\author{
Prepared by \\ OAK RIDGE NATIONAL LABORATORY \\ Oak Ridge, TN 37831-6283 \\ managed by \\ UT-BATTELLE, LLC \\ for the \\ US DEPARTMENT OF ENERGY \\ under contract DE-AC05-00OR22725
}





\section{CONTENTS}

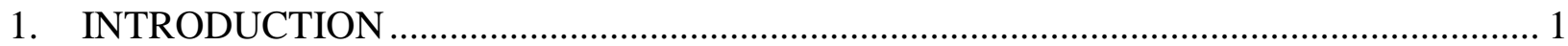

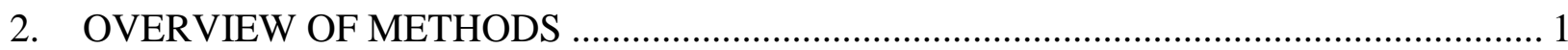

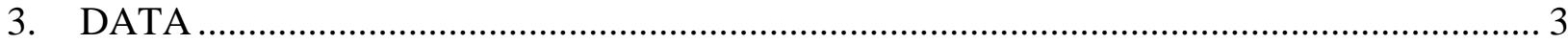

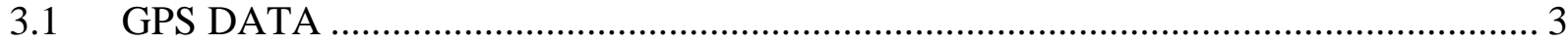

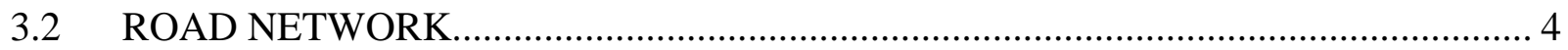

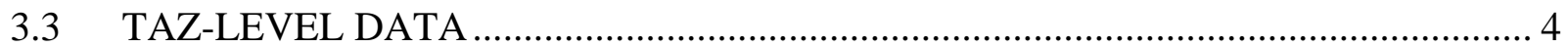

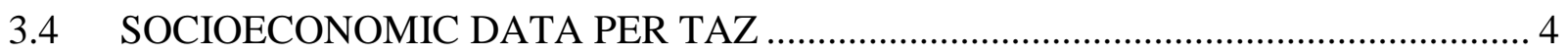

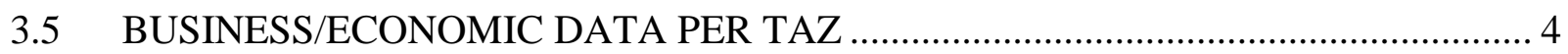

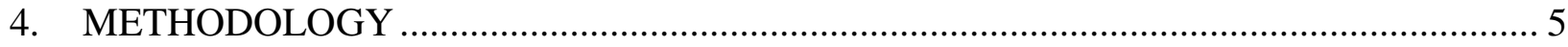

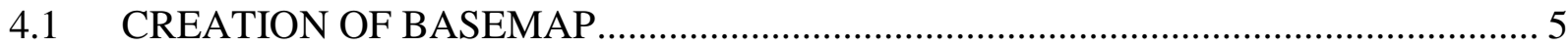

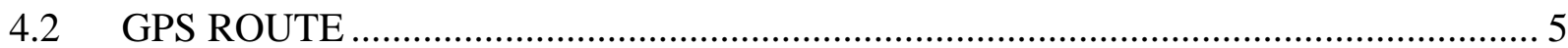

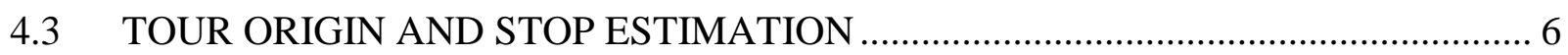

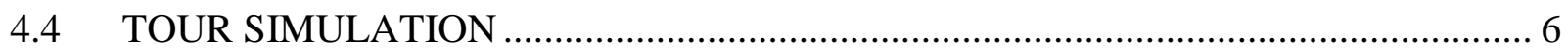

5. CASE STUDY DEVELOPMENT USING ALTERNATIVE MODES AND

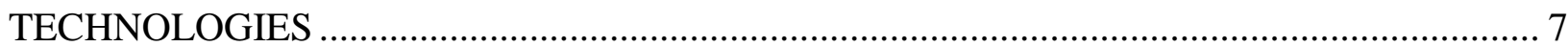

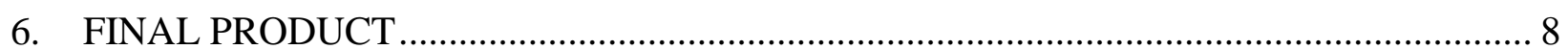

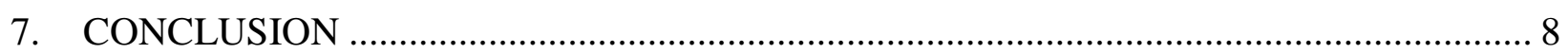

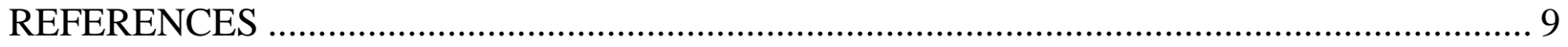




\section{INTRODUCTION}

This study is part of the US Department of Energy's Systems and Modeling for Accelerated Research in Transportation (SMART) Mobility initiative. It is included in the Multi-Modal pillar of SMART Mobility and is titled: Optimization of Intra-City Freight Movement and New Delivery Methods. The primary purpose of this study is to analyze the energy reduction opportunities provided by new freight modes and technologies. This will be done by developing a tour-based freight model for Columbus, Ohio. This model will be used to analyze the energy and emission savings of alternative technologies including drones, central delivery lockers, and the use of electric vehicles for last-mile freight deliveries. The tour-based model will also be used to examine the growth and distribution of freight traffic and its impacts on the local transportation system. Development of this model will be coordinated with the Mid-Ohio Regional Planning Commission (MORPC), the Metropolitan Planning Organization (MPO) for the Columbus, Ohio area.

In 2016, Columbus won the Smart City Challenge and received $\$ 40$ million from the US Department of Transportation (DOT), along with \$10 million from Vulcan, a philanthropic investment company founded by Paul G. Allen. As a "Smart City," Columbus plans to use smart technologies to: "improve people's quality of life, drive growth in the economy, provide better access to jobs and ladders of opportunity, become a world-class logistics leader, and foster sustainability" (MORPC, 2017). The tour-based freight model developed in this study will help Columbus in their objective to improve living conditions for Columbus residents by examining sustainable freight transportation options to reduce energy consumption and emissions, improving the existing transportation network and planning for future extensions to the existing network, streamlining intra-city goods movement, and improving safety in neighborhoods within the area.

In 2002, MORPC completed a freight impact study, which examined expected freight growth in the area, in which they stated that truck traffic will double by 2020. They also stated that approximately 33 percent of the measured truck traffic has an origin or destination within the area (MORPC, 2017). In this study, a tour-based freight model will be developed, which will help Columbus and MORPC to estimate future freight traffic growth in the area. The tour-based freight model can be incorporated into their existing model. The results of this study, along with the model, are expected to be beneficial for future freight and transportation infrastructure planning in the Columbus, Ohio area, and can be compared to the estimated freight traffic projections from the original 2002 study.

\section{OVERVIEW OF METHODS}

The methodology used in this study will be an extension of methods used in existing tour-based freight models and regional-level travel demand models. It will be similar to the model developed by the Maricopa Association of Governments (MAG): Phoenix, Arizona’s MPO. Currently, MAG has a regional travel demand model that was developed using Caliper's TransCAD software. MAG also has a tour-based freight model, which is part of their megaregional multi-modal agent-based behavioral freight model. TransCAD software was used to develop origin-destination matrices and to perform micro-simulation within the road network in 
both of these models, and R software was used to develop the discrete choice models used in the tour-based freight model. Currently, TransCAD software is used by many MPOs and regional planning entities to develop travel demand models. TransCAD, as shown in Figure 1, was chosen to be used in this study because it includes the routines needed to perform the key tasks required to develop a tour-based freight model. It is also widely-used by metropolitan planning agencies, so the model can be disseminated to a larger set of potential users. TransCAD's Geographic Information Systems Developer Kit (GISDK) scripting language will be used to perform batch processing and all of the necessary calculations in this study.

TransCAD will be used to develop a basemap for the model, which will contain the road network and various socioeconomic and business inventory data for Traffic Analysis Zones (TAZs). Detailed Global Positioning System (GPS) data from the United Parcel Service (UPS) will be obtained and plotted along the road network to document a subset of existing freight tours and provide additional data on average speeds on the road network. Linear regression will be used to estimate tour origins and stops within each of the approximately 7,000 TAZs within the Columbus metropolitan area. Freight flows along the road network will be estimated to model routes, representing potential tours using a version of Dijkstra's Algorithm in the form of a shortest path routine, which is available in TransCAD. Subsets of tours within TAZs, mainly neighborhoods, will also be modeled. These detailed analyses of small-scale case studies will be used to model last-mile energy savings using new technologies. Figure 2 shows the necessary data for model development and an overview of the project.

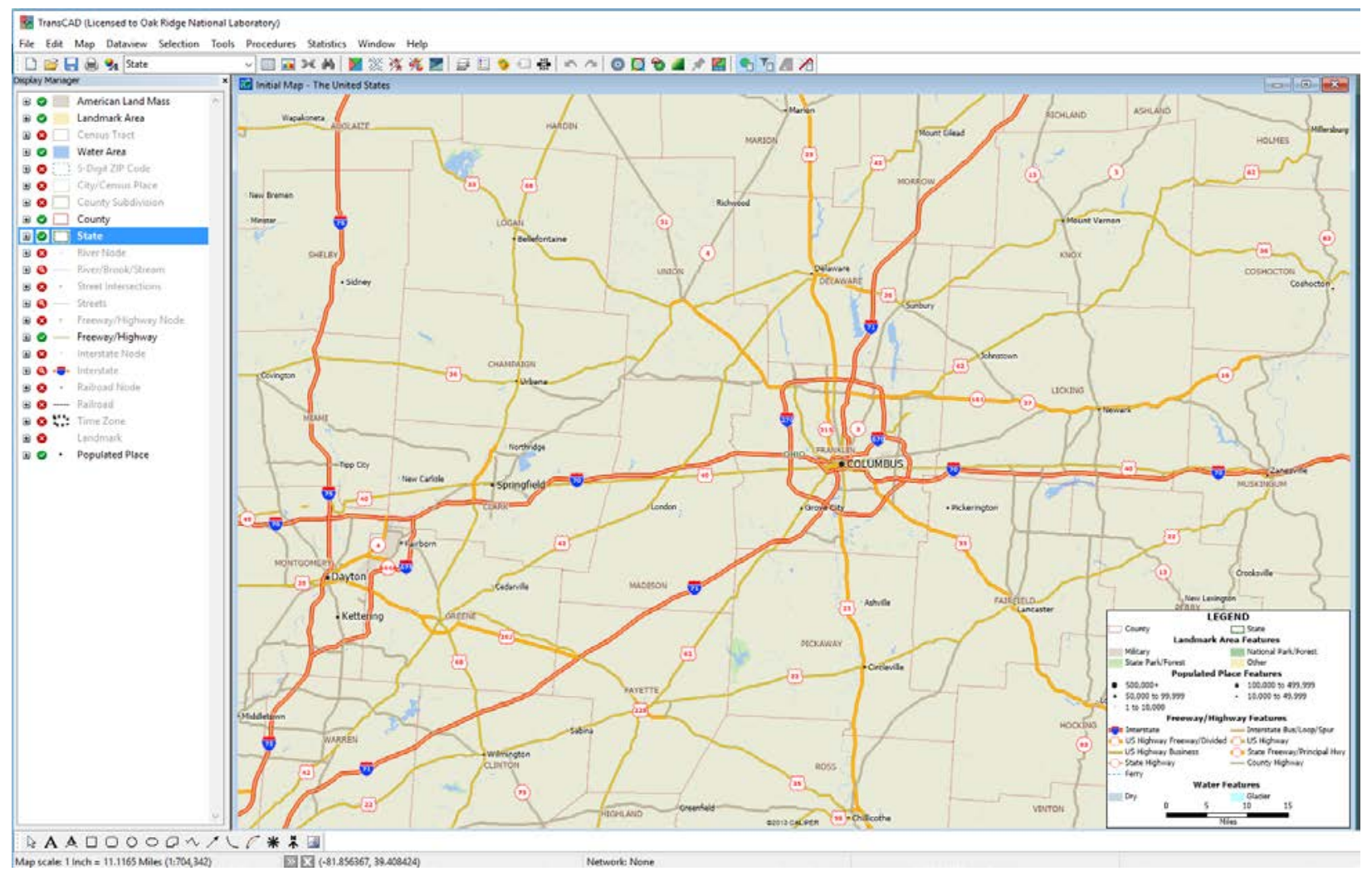

Figure 1. TransCAD Interface and Columbus Road Network 


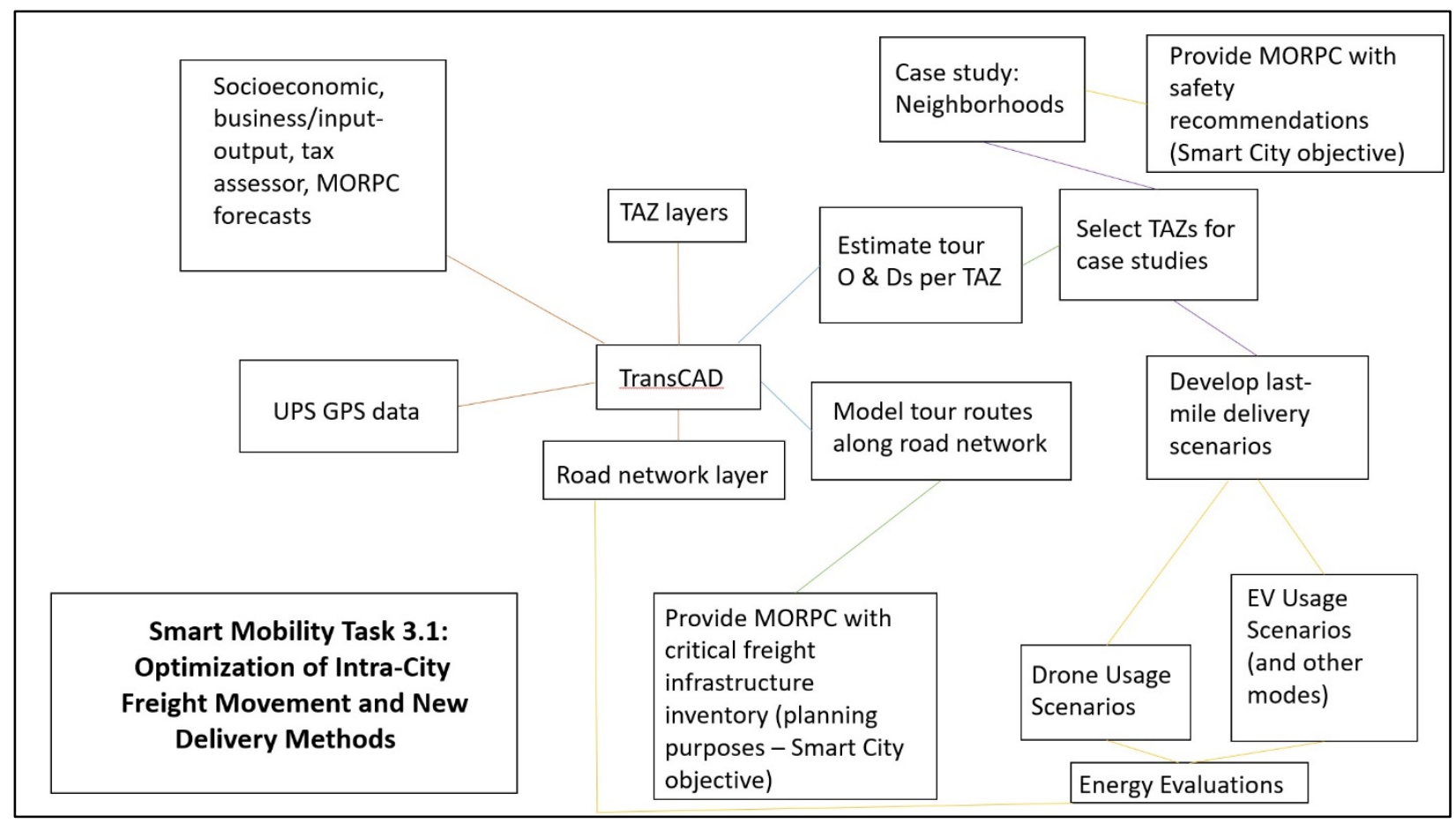

Figure 2. Project Overview

\section{DATA}

The model developed in TransCAD will require multiple types of data from a variety of sources in order to estimate the distribution of freight tour origins and stops throughout Columbus, and to estimate potential routing scenarios that will explore the energy saving potential of new technologies and delivery modes.

\subsection{GPS DATA}

UPS will provide detailed GPS data for their fleet for use in this study, along with information on trucks (truck type, energy usage, etc.), although most shipment information will remain confidential for privacy reasons. GPS trackers will be provided and affixed to a specified fleet of UPS delivery trucks (approximately 30 vehicles, with measured data from 30 days). The data obtained from the GPS trackers will be used to model routes in TransCAD. Information regarding average speeds, average number of stops on tours, length of stops, and general routes will be obtained from this data and used to develop estimates of the number of tour origins or stop locations along tours.

Additional GPS data may be needed for model development. The American Transportation Research Institute (ATRI) has GPS data obtained from trucks, and this data is commonly used for the purpose of model development and validation in previous tour-based freight modeling studies. Additional sources of GPS data may be needed to support development of the model. 


\subsection{ROAD NETWORK}

The road network for Columbus, which includes interstate highways, U.S. and state highways, arterials, connectors, and local roads, will be obtained from Tigerline files from the Census, which is included in the TransCAD package. The GPS data obtained from UPS (and possibly ATRI) will be modeled along the road network. Tour routes along the network links will be modeled to determine the potential tour routes. Average Annual Daily Traffic (AADT) data will need to be obtained from the Ohio DOT (ODOT), as well as any forecasted traffic data from MORPC and freight flow data and estimates from their existing model, and will be used to determine routes along the network, ultimately resulting in a least-cost or shortest path routine.

\subsection{TAZ-LEVEL DATA}

The geographic unit of analysis used in this study will be TAZs, as shown in Figure 3, which are commonly used in many travel demand forecast models. These units can be obtained through the Census, and contain census block-level, and sometimes census tract-level data. The area and dimensions of TAZs vary, depending on the location (denser, urban area TAZs are typically smaller in size). TAZs contain socioeconomic information obtained from the Census, related to car ownership, in order to estimate the number of origins and destinations per TAZ. Currently, MORPC has data by TAZ, which was used in their 2012 Metropolitan Transportation Plan.

\subsection{SOCIOECONOMIC DATA PER TAZ}

Although this is a freight model as opposed to the more common passenger vehicle models, and this is tour-based, rather than trip-based model, TAZ-level socioeconomic data is necessary to estimate tour production and attraction levels by location. Information regarding average number of households and average income levels per TAZ will help in estimating average number of deliveries to households, which is pertinent to UPS. This information will be necessary to estimate the number of stops within tours where UPS makes household deliveries.

\subsection{BUSINESS/ECONOMIC DATA PER TAZ}

TAZ-level data containing the number and sector-type of businesses is necessary for model development. This information will be used to estimate tour origins and stops based on business type per TAZ. The Columbus Chamber of Commerce will provide this information, along with county tax assessor parcel data. MORPC will be consulted to determine the sources of inputoutput data available. Input-output data is necessary to determine intra-city freight flows in Columbus. This information will also be necessary to estimate routes and tour stops based on commodities and various supply chain details involved in manufacturing within Columbus. North American Industry Classification System (NAICS) information from MORPC, the Columbus Chamber of Commerce, or the Regional Economic Model, Inc. (REMI) input-output model will be used to determine intra-city industry classifications and shipments in the Columbus area. 


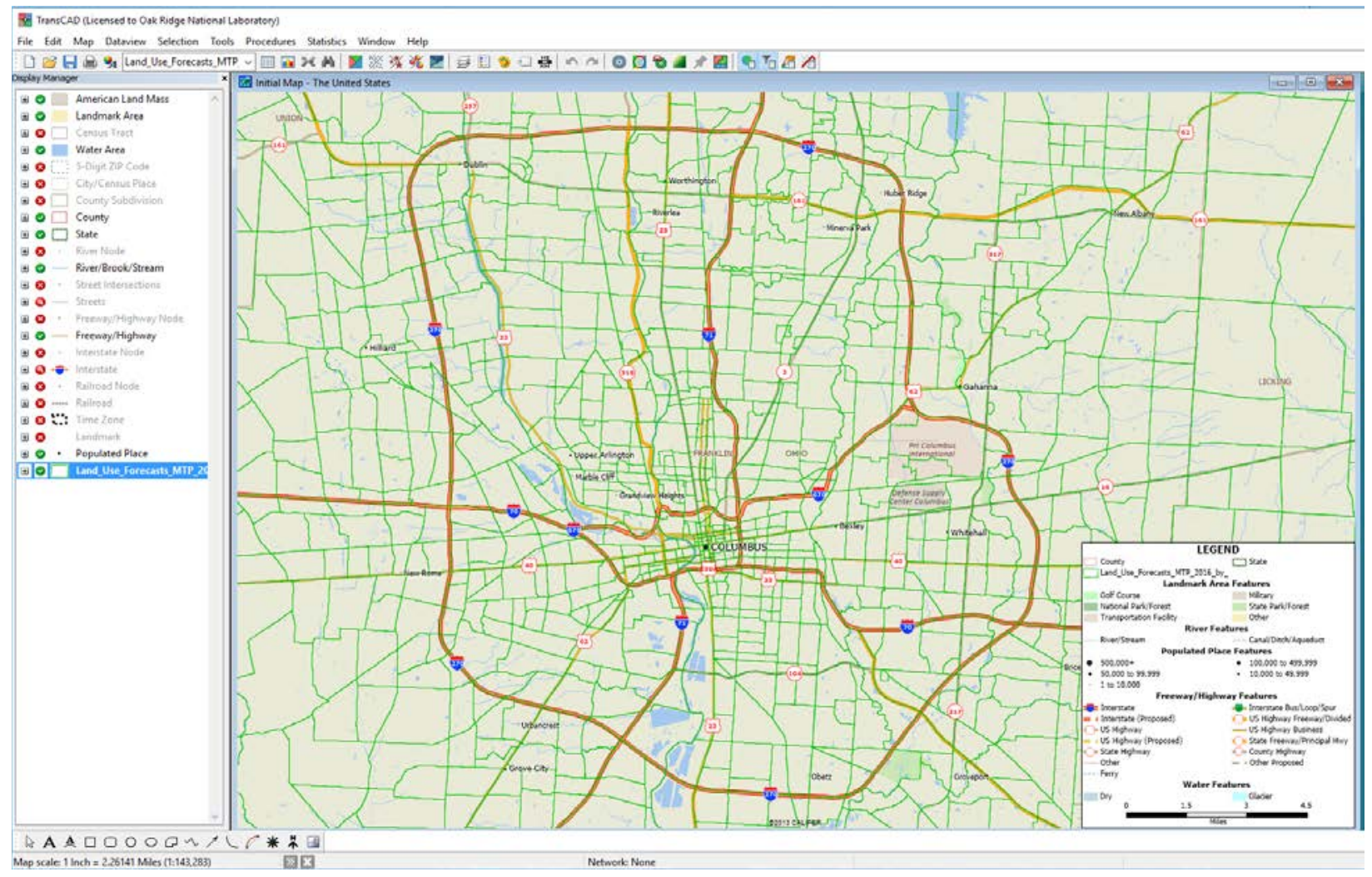

Figure 3. Columbus TAZs

\section{METHODOLOGY}

\subsection{CREATION OF BASEMAP}

The initial creation of a basemap in TransCAD will involve obtaining a polygon layer of the TAZ boundaries for the Columbus metropolitan area. This polygon file will contain the necessary socioeconomic data associated with each TAZ. The Census Tigerline polyline file representing the road network will be included in the basemap. This polyline file will have AADT and forecasted traffic data added to it. Each road segment "link" will have values associated with it to represent distance, speed, and ultimately congestion, on that link, which will be necessary to support the tour route estimation.

\subsection{GPS ROUTE}

After the initial basemap is created, the GPS data from UPS will be plotted along the road network. Using the GPS data, average speeds can be obtained for road segments along the network. If ATRI GPS data is also used, this will affect road segment congestion values based on average speeds. Tour origins and their associated stops can be determined based on the GPS data - where clustered GPS points represent stops (based on timestamp) along tours. Similar to the MAG tour-based freight model, this model will focus on medium or light-duty truck tours with 11 or fewer stops (MAG, 2017). 


\subsection{TOUR ORIGIN AND STOP ESTIMATION}

Using multiple linear regression analysis, the number of tour origins and stops will be estimated per TAZ. Linear regression and binary logistic regression can be performed within TransCAD using the Forecast function. This will simplify the procedure by performing the necessary calculations within the software, rather than importing back into the software from another software package. Separate regression equations will be developed for tour origins and stops, and separate regression equations will also be developed for different stop-types (retail, manufacturing, food service, residential, etc.).

The UPS GPS data will be plotted along the road network, and the TAZs where tour origins and stops/destinations will be determined based on clusters of GPS data points, timestamps, and speed data. After the route is plotted, the socioeconomic and business data will be extracted from the TAZs, which contain tour origins and stops. This data will then be used to perform the regression analyses to estimate number of tour origins and stops for each TAZ within Columbus. In terms of independent variables, such as those describing residents, including average income, number of households, etc. will be necessary for estimating tour stops within residential areas. For TAZs with businesses (retail, manufacturing, food services, etc.) employment numbers, land use types, and economic data from the regional input-output model will be used to estimate tour stops. Data regarding warehousing and manufacturing employment, industrial land uses, and input-output data will be necessary for estimating tour origin TAZ locations.

$$
Y=\beta_{0}+\beta_{1} X_{1}+\beta_{2} X_{2}+\ldots \beta_{k} X_{k}+\varepsilon
$$

Where $Y$ is the estimated number of origins or stops/destinations within a TAZ, and the regression coefficients $\left(\beta_{0}+\beta_{1}+\beta_{2}+\ldots \beta_{k}\right)$ will be determined, along with the residual $(\varepsilon)$.

\subsection{TOUR SIMULATION}

After performing the regression analyses, an estimated number of tour origins and stops will be estimated per TAZ. The TAZs that are estimated as being the potential location of a tour origin will be the starting points for the tour simulation. TransCAD's shortest path function will be used to determine the tour routes. This study is considering intra-city, or local area, freight transport, so a radius will be used to limit the distance from the origin: approximately 30 miles will be used as the limit (Schorpp, 2011). Based on previous studies, 11 stops per tour has typically been used in tour models involving medium and light-duty trucks (MAG, 2017). The UPS data will be used to understand the typical number of stops in Columbus, but, 11 is the expected maximum number of stops on a tour route. A shortest path routine will then be used to determine the route based on: the limited distance, the maximum number of stops, and the tour type (retail, manufacturing, food service, residential, etc.). The actual route will be determined based on congestion associated with the road network segments, which will be determined based on average speeds from the UPS GPS data, and any other available data (AADT, forecasted traffic data from MORPC, etc.). As representing in Figure 4, the route will ultimately be based on travel time, in order to limit the tours to less than eight hours (based on a typical work day). Variations of tour routes per origin will be modeled within TransCAD. Once the radius from the origin is 
specified, and the number of TAZs determined as stops for a specified tour-type, the route will be determined simply using the TransCAD routing function, which is based on Dijkstra's Algorithm, which will select road network links based on the travel time associated with each link. The route will be selected based on the least-cost path, making "stops" at each TAZ designated as a stop, and returning to the origin TAZ.

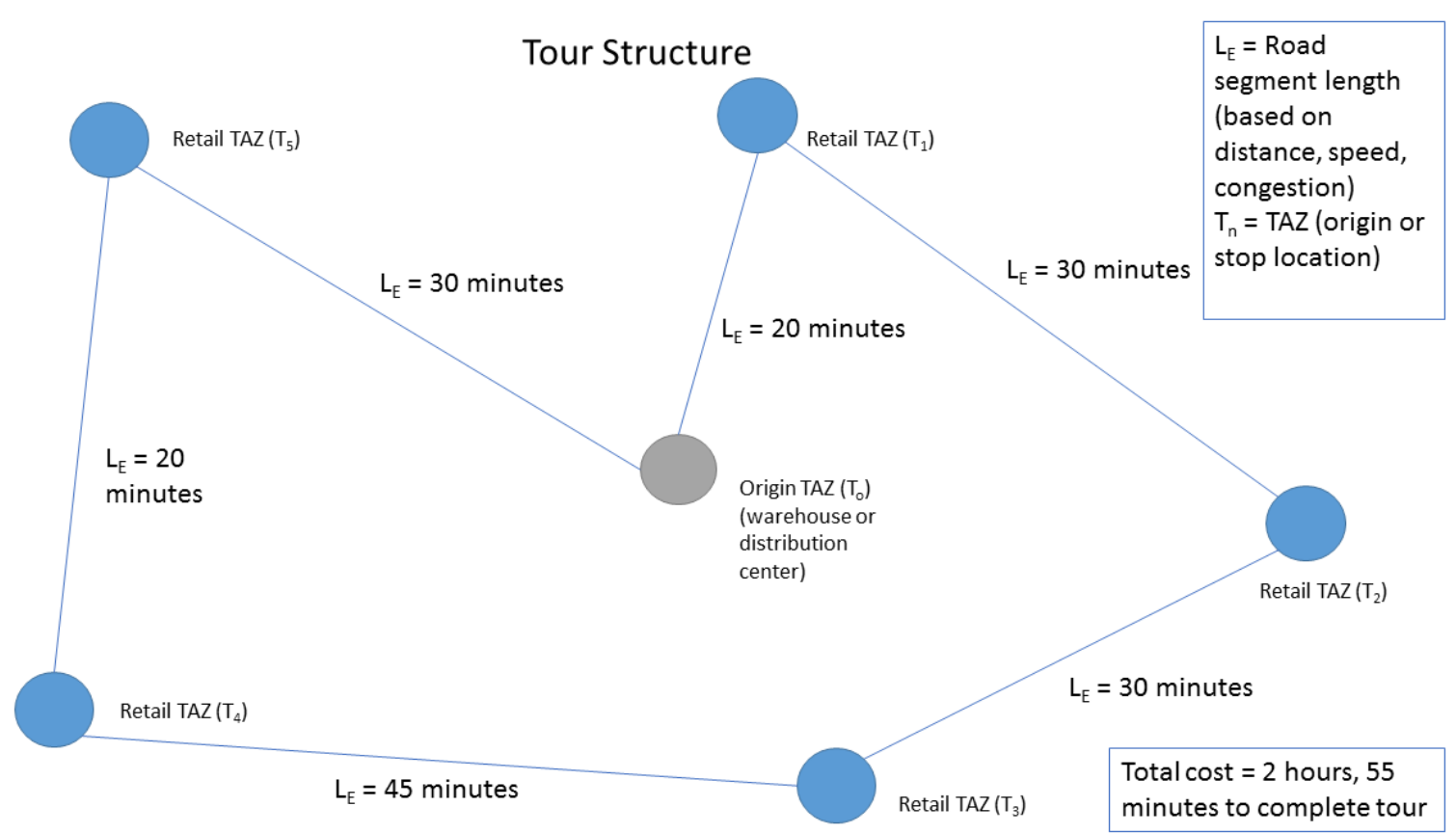

Figure 4. Basic Tour Structure

\section{CASE STUDY DEVELOPMENT USING ALTERNATIVE MODES AND TECHNOLOGIES}

A primary focus of this study involves consideration of last-mile scenarios and contrasting energy savings with the use of new technologies versus typical medium and light-duty truck usage. To explore this, TAZs with the highest number of tour stops, mainly residential neighborhoods, within Columbus will be chosen as case studies to model subsets of tours. These TAZs will be further explored to determine housing types and arrangements within the TAZs. Alternative delivery scenarios will then be examined to determine fuel usage and energy savings for last-mile deliveries within these TAZs.

Various types of alternative technologies will be considered for these case studies. Drones, central delivery lockers, and the use of electric vehicles will all be considered for these last-mile scenarios. Estimates of time savings, fuel usage, emissions, and ultimately energy savings will all be provided for each scenario. 


\section{FINAL PRODUCT}

This study is being performed to assist MORPC with planning, and the products of this study will be beneficial in a number of ways. The methods used in this study are not limited to Columbus. The methods used to develop this tour-based freight model in this study can be applied in other regions in the future.

The results of the tour-based freight model will provide MORPC with an estimate of heavily traveled road segments that may need improvements to accommodate the growth of freight traffic in the future. The results of the tour-based freight model will also provide MORPC with an estimate of the neighborhoods and areas with higher concentrations of pedestrian traffic that may require infrastructure improvements in the future to accommodate the growth of freight traffic in a way that is conducive to the safety of pedestrians and bicyclists. The results will also provide MORPC with alternative scenarios to reduce vehicular traffic (mainly trucks) in areas with higher concentrations of residents or employees by incorporating new technologies to make last-mile deliveries. These are all ways in which the results from the model developed in this study can benefit Columbus, and help MORPC in meeting its Smart City objectives.

\section{CONCLUSION}

This proposed methodology provides the basis for developing a next generation tour-based freight model that will support analysis of alternative last-mile delivery modes. Although the methods used in this study are similar to those used in previous studies, this study is a significant advance in that: it incorporates the use of proprietary data from a major parcel delivery company (UPS), and that it incorporates the usage of alternative technologies other than traditional truck usage for last-mile deliveries. These advances provide a better understanding of energy usage in freight delivery, and evaluates the potential of alternative energy-saving technologies. 


\section{REFERENCES}

Maricopa Association of Governments. (2017). MAG Next Generation Freight Demand Model. Final Report https://www.azmag.gov/Documents/TRANS_2017-02-13_SHRP2-C20MAG-Next-Generation-Freight-Demand-Model-Update.pdf Retrieved June 14, 2017 Mid-Ohio Regional Planning Commission (MORPC). 2017. Freight. http://www.morpc.org/transportation/freight/index

Schorpp, S. (2011). Dynamic Fleet Management for International Truck Transportation: Focusing on Occasional Transportation Tasks. Wiesbaden: Spring Gabler. 